\title{
IMAGING LOCAL SURFACE REACTIVITY ON STAINLESS STEELS 304 AND 316 IN ACID CHLORIDE SOLUTION USING SCANNING ELECTROCHEMICAL MICROSCOPY AND THE SCANNING VIBRATING ELECTRODE TECHNIQUE
}

J. Izquierdo ${ }^{1,2}$, L. Martín-Ruíz , B.M. Fernández-Pérez¹, L. Fernández-Mérida ${ }^{1}$, J.J. Santana ${ }^{3}$, R.M.

$$
\text { Souto }{ }^{1,2}
$$

${ }^{1}$ Department of Chemistry, University of La Laguna, E-38071 La Laguna (Tenerife), Spain.

${ }^{2}$ Instituto Universitario de Materiales y Nanotecnologías, University of La Laguna, E-38200 La Laguna (Tenerife), Spain.

${ }^{3}$ Department of Process Engineering, University of Las Palmas de Gran Canaria, E-35017 Las Palmas de Gran Canaria, Spain.

\begin{abstract}
Passive film breakdown and pit nucleation on 304 and 316 stainless steels in chloride-containing media were investigated using scanning microelectrochemical microscopy (SECM) and the scanning vibrating electrode technique (SVET). Experiments were performed for the alloys either at their corresponding open circuit potential, or under applied polarization, as to image domains of similar topography but different resistance against breakdown of the passive layers formed on these steels. Identification of the iron released species was accomplished, showing that pitting occurs with the formation of iron (II) species only. Detection of iron (III) species occurred when the steel sample was polarized at high positive overpotentials because it served as the reaction site to oxidize the iron (II) ions released from a propagating pit. The obtained results have revealed some difference of the reactivity of both specimens. Moreover the effect of the galvanic coupling has been investigated.
\end{abstract}

Keywords: 304 \& 316 stainless steels; Pitting corrosion; Scanning electrochemical microscopy; Scanning vibrating electrode technique; Chloride ions. 


\section{Introduction}

Local differences in chemical reactivity related to the development of microcells occur in the corrosion reactions, and they can be visualized in situ using scanning microelectrochemical techniques $[1,2]$, thus contributing to a better understanding of the behaviour of the system. Among them, scanning electrochemical microscopy (SECM) is a powerful technique for the investigation of the electrochemical processes occurring at the metal/electrolyte interface of corroding systems $[3,4]$. The scanning probe is usually an amperometric ultramicrodisk (tip) of a noble metal with diameter comprised between 10 and $25 \mu \mathrm{m}$, and it is moved in close proximity to the surface of the investigated material to characterize the electrochemically-active species participating in the process. This technique can be operated when the sample is either unbiased in the electrolyte, or under controlled polarization. In particular, the release of iron (II) ions from corroding iron-based materials can be detected at the tip through their oxidation to iron (III). This procedure has been successfully employed to image the metastable pitting of stainless steel [5], and the breakdown of passive oxide layers and subsequent localized corrosion on iron-based materials [6-11]. On the other hand, the $\mathrm{Fe}^{2+} / \mathrm{Fe}^{3+}$ couple undergoes a reversible redox reaction in acidic environment, so in principle the release of iron (III) species could also be imaged over reacting samples from their reduction to ferrous species. Yet this possibility has not been exploited for corrosion research using the SECM, mainly because iron (II) ions are produced in significant amount to be adequately detected in most corrosion problems concerning iron-based materials, whereas ferric ions have a strong tendency to precipitate as iron (III) oxy-hydroxides and they may accordingly block the surface of the sensing probe. Alternately, another electrochemically-active species often monitored in SECM studies of corroding systems is the molecular oxygen dissolved in the solution $[6,7]$. In this case, a redox competition effect between the measuring tip and the sample under investigation occurs when this molecule is consumed in the cathodic sites [12].

Another scanning microelectrochemical method successfully employed to study corrosion processes and systems is the scanning vibrating electrode technique (SVET) [13]. It images the ionic fluxes of species involved in the electrochemical processes occurring on surfaces, especially those participating in the corrosion reactions [14-22]. Thus, the location of any electrochemical reaction that occurs over an area is detected as long as it originates measurable ionic fluxes over it, allowing the distribution of cathodic and anodic places on the metallic surfaces to be imaged. Such information is relevant to identify the places where the corrosion process can start. A major advantage of SVET is that use of a potentiostat is not required, thus effectively leaving the metallic sample at its corrosion potential in the environment. In fact, external polarization of the substrate has been seldom performed for the characterization of corrosion reactions using SVET $[14,18,19]$. This is probably due to the loss of sensitivity encountered when the sample is polarized, because the reference signal employed to measure the ionic current fluxes cannot be taken in a position with 
the adequate symmetry with relation to the auxiliary electrode electrochemical control and polarization of the surface under study. Furthermore, systems experiencing corrosion produce heterogeneous distributions of the corroding microcells that are not symmetrically located in relation to an otherwise perfectly symmetrical auxiliary electrode, thus leading to inhomogeneous current fluxes in the solution. Despite these difficulties, still some valuable information can be collected on polarized substrates, as it will be demonstrated in this work. With this information, passivity breakdown of the passive layer and stable pitting corrosion could be simultaneously studied through the global transient currents and the local ionic current produced as result.

It is well known that 304 and 316 stainless steels are susceptible to pitting corrosion in chloride solution due to localized breakdown of the passive oxide layers. The aim of this work was to visualize local reactivity distributions related to passivity breakdown of 304 and 316 stainless steels promoted by sample polarization while the materials were immersed in aqueous chloride solutions of different composition. The nature and extent of corrosion processes on the two stainless steels were investigated at micro-scale using SECM and SVET. Stable pit growth has been followed by detecting the release of soluble iron ions from the corroding metal, and its dependence with both the applied potential and the composition of the test environment.

\section{Experimental section}

Experiments were performed on 304 and 316 grade austenitic stainless steel supplied as sheet of thickness $1 \mathrm{~mm}$ by Goodfellow Materials Ltd, Cambridge, UK. The metals were not analysed, but the nominal compositions provided by the manufacturer were:

- 304 stainless steel: $17-20 \% \mathrm{Cr}, 8-11 \% \mathrm{Ni},<2 \% \mathrm{Mn},<0.08 \% \mathrm{C}$, bal. Fe.

- 316 stainless steel $16.5-20 \% \mathrm{Cr},<2 \% \mathrm{Mn}, 8-14 \% \mathrm{Ni},<0.12 \% \mathrm{C}, 2.0-3.5 \% \mathrm{Mo}$, bal. Fe.

Samples were fabricated from $1 \mathrm{~mm}$ thick sheets of the steels. They were cut into ca. $2 \mathrm{~mm}$ width and $2 \mathrm{~cm}$ length strips, and mounted in an Epofix (Struers, Ballerup, Denmark) resin sleeve of approximate diameter $3 \mathrm{~cm}$, so that only $1 \mathrm{~mm} \times 2 \mathrm{~mm}$ metallic areas were exposed to the electrolyte. The resulting mounts contained one strip of each material. These samples were abraded using SiC paper of 1200 and 4000 grit, and subsequently polished using alumina suspension $0.3 \mu \mathrm{m}$ particle size. The strips of the two steels protruded at the rear of the mount to facilitate electrical connection. In this way, they could be either connected between them to form a galvanic pair, or polarized by an external potentiostat. When only one surface was investigated, the other metallic strip was covered by sellotape in order to prevent any eventual interference resulting from its exposure to the electrolyte.

SECM experiments were carried out in $0.25 \mathrm{M}$ and $0.1 \mathrm{M} \mathrm{HCl}$ test solutions, whereas SVET measurements were done in $0.025 \mathrm{M} \mathrm{HCl}+0.075 \mathrm{M} \mathrm{HClO}_{4}$. The latter was chosen as to produce a 
less aggressive attack on the alloys whereas maintaining the same $\mathrm{pH}$ in solution as in $0.1 \mathrm{M} \mathrm{HCl}$. All the reagents were of analytical grade and solutions were prepared by using twice distilled water. Experiments were performed at ambient temperature in the naturally aerated solutions.

SECM measurements were performed with equipment purchased to Sensolytics GmbH (Bochum, Germany). The instrument was built around an Autolab (Metrohm, Herisau, Switzerland) bipotentiostat, controlled by personal computer. Platinum microdisks of $10 \mu \mathrm{m}$ diameter were employed as microelectrode tips. The small electrochemical cell (ca. $3.5 \mathrm{~mL}$ volume) contained an $\mathrm{Ag} / \mathrm{AgCl} / \mathrm{KCl}(3 \mathrm{M})$ reference electrode, and a platinum counter electrode. The system was operated in either three-electrode or four-electrode configuration depending on whether the potential of the substrate was left unbiased or under potentiostatic control.

Scanning Electrochemical Microscopy was operated in the Substrate Generation - Tip Collection (SG/TC) mode to detect either iron (II) or iron (III) cations evolving from stainless steel surfaces under different substrate polarization. Tip to substrate distance was established by recording approach curves in the negative feedback mode towards the surrounding insulating sleeve. The tip potential was set at $-0.65 \mathrm{~V}$ vs. $\mathrm{Ag} / \mathrm{AgCl} / \mathrm{KCl}(3 \mathrm{M})$ in order to register the faradaic current related to the reduction of dissolved oxygen. After the surface was located, the tip was withdrawn $10 \mu \mathrm{m}$ for scanning parallel to the sample. Both linear scans and 2D maps were recorded at maximum scan rate of $25 \mu \mathrm{m} \mathrm{s}^{-1}$. Tip potential was alternately set at +0.50 and $+0.10 \mathrm{~V}$ vs. $\mathrm{Ag} / \mathrm{AgCl} / \mathrm{KCl}(3 \mathrm{M})$ to detect iron species of different oxidation states. The first value was employed to detect iron (II) species through their oxidation at the microdisk. Tip potential was set at $+0.10 \mathrm{~V}$ for the eventual reduction of iron (III) species evolving from the substrate while polarized more positive than $+0.30 \mathrm{~V}$ vs. $\mathrm{Ag} / \mathrm{AgCl} / \mathrm{KCl}(3 \mathrm{M})$

SVET experiments were conducted with an Applicable Electronics Inc. instrument (Forestdale, MA, USA). The sensing probes were $10 \mu \mathrm{m}$ PtIr wires. They were electrochemically deposited black platinum until they provided adequate capacitance values. Probe vibration in normal direction to the surface was applied, with $75 \mathrm{~Hz}$ vibration frequency, with $20 \mu \mathrm{m}$ amplitude vibration. The substrate to probe distance was fixed at $60 \mu \mathrm{m}$. Sample polarization was performed in this case using a potentiostat/galvanostat Model 283 (Princeton Applied Research, Oak Ridge, TN, USA). The current and potential analogic outputs of the potentiostat were connected to analog inputs of the SVET instrumentation, so these two parameters were also monitored in the experiments. A platinum ring covered with black platinum electrodeposit was employed as the counter electrode to minimize asymmetries in current distribution due to the geometry of the system, and an $\mathrm{Ag} / \mathrm{AgCl} / \mathrm{KCl}(3 \mathrm{M})$ was used as reference electrode.

\section{Results and discussion}


Changes in chemical activity related to corrosion of stainless steel 304 and 316 samples left at their spontaneous open circuit potential during immersion in $0.25 \mathrm{HCl}$ solution were monitored using SECM operated in the SG/TC mode. The tip potential was set at $+0.50 \mathrm{~V} v \mathrm{vs} . \mathrm{Ag} / \mathrm{AgCl} / \mathrm{KCl}$ (3M) in order to monitor the oxidation of dissolved iron (II) into iron (III) species.

Figure 1 displays the time evolution of iron (II) generation from a 304 stainless steel sample in $0.25 \mathrm{HCl}$. During the first recorded scan, given in Figure $1 \mathrm{~A}$, high current values in the order of 100 pA were initially registered, evidencing rather high iron dissolution rates leading to the release of bivalent cations. However, current decreased quite abruptly after recording a few scan lines over the metal, and it only increased again towards the end of the scan. This behaviour is characteristic of a system that evolves faster than the time required for the tip to acquire the data, though the occurrence of heterogeneous electrochemical behaviour over the steel strip cannot be discarded yet. Immediately after this scan was recorded, the procedure was repeated to obtain the image depicted in Figure 1B. This second scan evidenced a more homogeneous distribution of metal ions over the sample. Though at the beginning of the scan the tip current values were close to those measured at the end of the previous scan, a sustained increase with time was observed reaching up to $0.9 \mathrm{nA}$. Changes in the chemical activity of the exposed surface occurred now at a slower rate, although the tip was still unable to complete one scan of entire metal strip before relevant change took place over the sample. The following scan in Figure 1C, taken after 7.5 hours immersion, shows that metal dissolution happened over the complete exposed steel strip. A less active surface was then imaged, as evidenced by the smaller current values recorded in this map. Finally, after 24 hours immersion, metal dissolution from the surface had greatly diminished due to metal passivation, and the smaller tip currents were related to the background passivation current (cf. Figure 1D). Then, no complete passivation was observed for this steel in this aggressive environment.

\section{Figure 1}

Imaging of 316 stainless steel was performed in the same conditions, and it evidenced a much less active surface. The images given in Figure 2 show tip current values below 100 pA, significantly smaller than those previously recorded for 304 steel (cf. Figure 1). Moreover, only the two first scans, initiated after 25 and 158 minutes immersion in the acid solution, detected iron (II) generation from the substrate, whereas the signals measured in subsequent scans could not be resolved from background noise. First scan acquired with the SECM, displayed in Figure 2A, suggests a rather homogeneous distribution of electrochemical activity for 316 steel in this aggressive media that allows the contour of the steel strip to be clearly distinguished from the surrounding epoxy sleeve. Yet, electrochemical activity is exclusively related to the onset of passivation, and only a small release of metal ions due to localized corrosion occurred near the centre of the strip during the second scan.

Figure 2 
Effect of polarization on the chemical activity of the two steels during immersion in $0.25 \mathrm{HCl}$ solution was next investigated by SECM. In this case, the samples were polarized anodically with respect to their corresponding OCP values using the bipotentiostat built in the SECM instrument. For that purpose, one scan was firstly taken after immersion of each sample in $0.25 \mathrm{M} \mathrm{HCl}$ at its corresponding OCP. Then, OCP was measured before applying positive polarization to the metal substrate and scanning again. The resulting images for both surfaces are shown in Figure 3A-B, respectively. The OCP values measured after completing those scans were -0.26 and $-0.16 \mathrm{~V}$ vs. $\mathrm{Ag} / \mathrm{AgCl} / \mathrm{KCl}(3 \mathrm{M})$, for 304 and 316 steels, respectively. These values correspond well with the electrochemical characteristics of both steels. Again rather homogeneous distributions of iron (II) species released from the freshly exposed samples were observed, and the contours of the samples were clearly distinguished in the images. When the substrate was biased at $-0.10 \mathrm{~V}$ vs. $\mathrm{Ag} / \mathrm{AgCl} / \mathrm{KCl}(3 \mathrm{M})$ (see Figures 3C-D), which is indeed an anodic polarization with respect to their corresponding OCP values, metal dissolution occurred in a more heterogeneous way, leading to enhanced release of iron (II) from sites close to the metal edges. Crevice corrosion might originate from imperfect joint between the insulating resin and the active metal. Still, current values are four times smaller for the nobler 316 surface. The crevice corrosion effect was likely to happen in the system when sample polarization was shifted even more anodically to $+0.05 \mathrm{~V} \mathrm{vs}$. $\mathrm{Ag} / \mathrm{AgCl} / \mathrm{KCl}$ $(3 M)$, as it is shown in Figures 3E-F for 304 and 316 surfaces, respectively. Tip currents were in the nA range with this polarization for both substrates, though 3 - 4 times bigger for the more active 304 surface. Besides, the substrate currents were measured using the current amplifier function of the bipotentiostat during the duration of the experiment. They ranged between 0.1 and $1.25 \mathrm{~mA} \mathrm{~cm}^{-2}$ for the 316 strip, and between 0.25 and $15.9 \mathrm{~mA} \mathrm{~cm}-2$ for 304 steel. These are rather high current densities related to localized corrosion of the stainless steels.

\section{Figure 3}

Experiments were next performed in $0.1 \mathrm{M} \mathrm{HCl}$ in order to reduce the impact of localized corrosion by using a less concentrated solution. Furthermore, the two steels were exposed simultaneously, and the effect of galvanic coupling could also be considered in the same experiment. In this way, a more direct comparison of the electrochemical behaviours of the two steels and their evolution with time could be performed in situ. Due to the very large area required to image both steels in one single scan (in excess of $6000 \mu \mathrm{m} \times 2000 \mu \mathrm{m}$ ), thus requiring very large times for recording one single SECM image, scan lines passing through both steel strips were recorded instead. For the sake of reproducibility, several lines were taken at different positions over the two steels strips to more accurately characterize the behaviour of the two steels.

SECM was firstly employed to image ferrous ions evolving from both steel surfaces (i.e., setting $E_{\text {tip }}=+0.50 \mathrm{~V}$ vs. $\left.\mathrm{Ag} / \mathrm{AgCl} / \mathrm{KCl}(3 \mathrm{M})\right)$. Figure 4 shows selected scan lines recorded over the sample containing 304 and 316 steel strips at four different electrical conditions of the substrate. Metal release was only observable over the 304 steel when the samples were either left unbiased, 
or galvanically-coupled by producing an electric contact between both steels at the rear of the mount. It should be noticed that greater tip currents related to detection of released iron (II) from the 304 strip occurred when the sample was left unbiased (cf. Figures 4A-B). Since 316 is less active material than 304 steel, it could be expected galvanic coupling to promote anodic dissolution of the latter, resulting in the measurement of greater currents at the tip over this alloy. But it must be noticed that galvanic coupling was produced after recording the scan lines in Figure $4 \mathrm{~A}$, and the surfaces would be somewhat passivated in the medium at the time of coupling. This passive layer was effectively protecting both materials from undergoing further iron oxidation when they were simultaneously polarized at potentials between 0 and $+0.20 \mathrm{~V} \mathrm{vs}$. $\mathrm{Ag} / \mathrm{AgCl} / \mathrm{KCl}(3 \mathrm{M})$, since only noise was detected as tip current.

\section{Figure 4}

The situation changed for more positive polarizations of the samples, starting when $+0.25 \mathrm{~V}$ vs. $\mathrm{Ag} / \mathrm{AgCl} / \mathrm{KCl}(3 \mathrm{M})$ was applied (see Figure $4 \mathrm{C}$ ). In this case, the scan line measured at $Y=200$ $\mu \mathrm{m}$ shows a current peak amounting ca. 90 pA, again only over the more active metal 304, showing the onset of localized corrosion. In order to check whether enhanced metal dissolution at this position should be attributed to nucleation of a metastable pit because the substrate potential was below the corresponding pitting potential of 304 steel in $0.1 \mathrm{M} \mathrm{HCl}$ [23], the direction of the tip scan was reverted without shifting the $Y$ position. Repassivation of the pit did not occur, because even greater tip currents related to the release of $\mathrm{Fe}(\mathrm{II})$ ions were measured when the tip passed over the same position approximately 8 min later. Scan lines taken at other positions did not exhibit current signals distinguishable from the background noise levels. A more anodic polarization, namely +0.30 $\mathrm{V}$ vs. $\mathrm{Ag} / \mathrm{AgCl} / \mathrm{KCl}(3 \mathrm{M})$, led to vigorous release of iron (II) ions above all the extension of the 304 steel strip, as well as a smaller metal release from the 316 strip as well, as observed for $Y=800 \mu \mathrm{m}$ in Figure 4D. The same scan line also exhibited two peaks over the 304 surface, revealing either edge effects for steel dissolution, or eventually iron (II) oxidation to iron (III) ions on the surface and subsequent depletion in ferrous concentration and tip current. In order to test the validity of the latter, scan lines were recorded after switching $E_{\text {tip }}$ to $+0.10 \mathrm{~V}$ vs. $\mathrm{Ag} / \mathrm{AgCl} / \mathrm{KCl}(3 \mathrm{M})$, that iron (III) species could be detected by reduction at the tip. But only the noise level signal was detected in this way, thus discarding the formation of $\mathrm{Fe}(\mathrm{III})$ species at this polarization. Higher anodic polarization of both steel surfaces did not allow detection of soluble iron species over the 316 stainless steel, since the major dissolution of the metal from the 304 strip was diffusing into the solution even further from the strip and could be detected increasingly closer to the noblest specimen. Therefore, detailed investigation of the effect of polarization on the corrosion behaviour of 316 steel by SECM had to be performed when only this strip was exposed to the corroding environment.

Then, the same sample mount, freshly polished and cleaned, and with the 304 surface covered by adhesive tape to avoid exposure to the electrolyte, was immersed in $0.1 \mathrm{M} \mathrm{HCl}$ solution, and scan lines were recorded over the 316 surface in the same way as before. The scan lines 
recorded for the unbiased steel, as well as those with sample polarization below $+0.30 \mathrm{~V}$ vs. $\mathrm{Ag} / \mathrm{AgCl} / \mathrm{KCl}(3 \mathrm{M})$ only showed noise level signals at the tip. That is, polarization equal or more positive than $+0.30 \mathrm{~V}$ vs. $\mathrm{Ag} / \mathrm{AgCl} / \mathrm{KCl}(3 \mathrm{M})$ was required to promote detectable local dissolution of iron over the steel surface, as it is shown in Figure 5. When the substrate was biased at $+0.30 \mathrm{~V}$ vs. $\mathrm{Ag} / \mathrm{AgCl} / \mathrm{KCl}(3 \mathrm{M})$, some of the scan lines taken over the steel surface showed local anodic dissolution of iron with the formation of iron (II) species (cf. lines recorded at $Y$ position $1100 \mu \mathrm{m}$ in Figures $5 A-B$ ). Upon detection of iron (II) species in these scan lines, the tip potential was shifted to $+0.10 \mathrm{~V}$ vs. $\mathrm{Ag} / \mathrm{AgCl} / \mathrm{KCl}(3 \mathrm{M})$ to reduce any eventual iron (III) species evolving from surface (red data in graph). In this case, a weak increase in cathodic current over the reactive material was found, probably due to formation of ferric ions on the surface and their reduction at the probe. This fact was more noticeable when the substrate was polarized at $+0.40 \mathrm{~V} \mathrm{vs}$. $\mathrm{Ag} / \mathrm{AgCl} / \mathrm{KCl}(3 \mathrm{M})$ as shown in Figures 5C-D. In that case, the whole area seemed to be activated for the formation of iron (III) species, though apparently in different ways. Specifically, the current measured at the tip biased at $+0.50 \mathrm{~V}$ vs. $\mathrm{Ag} / \mathrm{AgCl} / \mathrm{KCl}(3 \mathrm{M})$ was smaller while the tip was moved over the steel strip, showing local depletion in iron (II) concentration, whereas an evident cathodic current was measured in the same region when the tip potential was set at $+0.10 \mathrm{~V}$ vs. $\mathrm{Ag} / \mathrm{AgCl} / \mathrm{KCl}(3 \mathrm{M})$. That is, the cathodic currents related to the reduction of iron (III) ions were recorded precisely in the same positions where less iron (II) was monitored.

\section{Figure 5}

Two additional features can be found from observation of the graphs in Figure 5 that would require further discussion. Firstly, bigger anodic currents were measured over the surrounding epoxy sleeve as the substrate was polarized at more positive potential with the tip biased at $+0.5 \mathrm{~V}$ vs. $\mathrm{Ag} / \mathrm{AgCl} / \mathrm{KCl}(3 \mathrm{M})$, indicating greater diffusion of ferrous metal ions into the surrounding volume of the electrolyte. Secondly, SECM scan lines recorded with the tip potential set at $+0.10 \mathrm{~V}$ vs. $\mathrm{Ag} / \mathrm{AgCl} / \mathrm{KCl}(3 \mathrm{M})$ also showed an anodic current branch following the measurement of the cathodic currents assigned to the reduction of iron (III). Increased concentration of iron (III) ions in the volume adjacent to the steel surface in the case of the more anodic polarization of the substrate can also originate from oxidation at the metal of the iron (II) ions released from the corroding substrate, since the steel surface was polarized at a potential value high enough to sustain their oxidation if the passive film was broken. The origin of the anodic currents observed at the end of the scan lines measured with $E_{\text {tip }}=+0.10 \mathrm{~V}$ vs. $\mathrm{Ag} / \mathrm{AgCl} / \mathrm{KCl}(3 \mathrm{M})$ remains still unknown, though it may be related to the formation of hydrogen peroxide on the substrate, and this species can be oxidized at the tip. Indeed, a similar feature has been previously reported accompanying the degradation reactions occurring from defects in painted steel samples under potentiostati polarization [24].

Another effect was discovered by monitoring the total current flowing through the substrate during SECM experiments. It occurred when the substrate was polarized at the highest anodic polarizations under consideration, that is, when localized corrosion was detected by SECM. In 
principle, it should be expected that the current measured at the substrate must be an average measurement of the electrochemical processes occurring on the total steel surface exposed to the electrolyte, and they should be exclusively related to the electrical state of the sample and the composition of the electrolyte. Thus, no significant influence should be produced by the local shielding of the small tip when it scanned parallel to the surface. Nevertheless, Figure $6 \mathrm{~A}$ shows changes in the plots of the substrate current when the tip passed above the steel strip. That is, major decrease of the faradaic current flowing from the sample happened when the tip was passing over the 304 steel strip but not over the 316 steel strip, though they were both potentiostatically polarized at the same potential (namely, $+0.35 \mathrm{~V}$ vs. $\mathrm{Ag} / \mathrm{AgCl} / \mathrm{KCl}(3 \mathrm{M})$ ). This feature relates to the presence of the tip in close proximity to the substrate is further evidenced by observing that the current traces at either side of the 304 steel strip could be connected in a continuous line if the values over the metal were ignored. Next, the magnitude of the effect caused by the moving tip on the substrate decreased with the elapse of time, and it was mostly independent of the potential value applied to the tip. That is, it may be regarded independent of whether iron (II) or iron (III) species are locally consumed at the tip.

\section{Figure 6}

Modification of the current response of the substrate by the passage of the tip parallel to the substrate was also found when only the 316 surface was exposed to the surface. In this case, a more anodic polarization was required to detect some changes (i.e., $+0.40 \mathrm{~V} v \mathrm{vs} . \mathrm{Ag} / \mathrm{AgCl} / \mathrm{KCl}(3 \mathrm{M})$ ). The progressive deactivation of the steel surface related to passive layer generation is also viewed in Figure $6 \mathrm{~B}$ in the form of greater changes in the substrate current when the tip passed above the metal sample. Again the effect is observed to be independent of the potential applied to the tip. The justification of this feature remains uncertain at present, though it is clearly related to changes in the composition of the electrolyte, which may reduce the susceptibility to passive film breakdown. Since this effect is apparently independent of tip potential, this change might be related to electrolyte convection promoted by movement of the tip, rather than to any eventual electrochemical process taking place at the tip. Actually, hydrolysis of iron cations may produce local acidification and subsequent increase of the aggressiveness of the surrounding electrolyte, so renewal of the solution produced by the tip movement may decrease this aggressiveness, allowing steel surfaces to be repassivated at least to some extent.

With the objective to gain additional insights on the local reactivity of steels related to passive layer breakdown in acid chloride solution, the scanning vibrating electrode technique was also employed. This technique allows ionic current flows to be measured in the electrolyte with high spatial resolution provided low conductivity electrolytes are employed. In fact, concentrated electrolytes lead to loss of sensitivity. If ionic strength is high in the bulk solution, ions produced or consumed in active regions correspond to charges easily compensated by counter ions from the bulk solution, with the outcome that concentration and charge gradients become less defined. Next, 
when vigorous formation or consumption of ionic species happens at an active site on the surface, the resistivity of the electrolyte volume next to the site is greatly modified. Considering that SVET measurement involves conversion of a sinusoidal potential signal into an ionic density current signal through the simple application of Ohm's law, which contains the value of the solution resistivity, highly aggressive electrolytes may promote a vigorous metal dissolution process and the SVET response would not be sufficiently accurate. Therefore, the corrosion behaviour of coupled 304 and 316 steel strips was further investigated in a less concentrated chloride solution. However, protons activity was maintained the same in order to prevent repassivation of nucleated corrosion pits. Mounts containing strips of the two steels surfaces, were investigated by SVET in $0.025 \mathrm{M} \mathrm{HCl}+$ $0.075 \mathrm{M} \mathrm{HClO}_{4}$. Both steel strips were electrically connected at the rear of the mount, in order to impose the same polarization to them by the application of an external polarization with a potentiostat. The potential of the substrate was set at several values between -0.75 and $+1.20 \mathrm{~V}$ vs. $\mathrm{Ag} / \mathrm{AgCl} / \mathrm{KCl}(3 \mathrm{M})$ in steps, somewhat resembling the procedure employed in recording potentiostatic polarization curves. A SVET image was recorded at each potential value. Selected scans are displayed in Figure 7. Polarization at $-0.75 \mathrm{~V}$ vs. $\mathrm{Ag} / \mathrm{AgCl} / \mathrm{KCl}(3 \mathrm{M})$ only shows ionic currents related to the reduction of protons on both metal strips (Figure 7A). No major differences were found between the two steels concerning this cathodic reaction, though the distribution of the maximum ionic currents depicted as deep blue (corresponding to ca. -250 to $-300 \mu \mathrm{A} \mathrm{cm}{ }^{-2}$ ), seems to be more extended over the 304 strip leading to a rather homogeneous appearance. Similar ionic current distributions were obtained at potentials more negative than their OCP.

\section{Figure 7}

Anodic polarization was initiated at $0 \mathrm{~V}$ vs. $\mathrm{Ag} / \mathrm{AgCl} / \mathrm{KCl}(3 \mathrm{M})$, but only background noise was obtained. This behaviour remained for increasingly positive polarizations, and it was necessary to apply $+0.45 \mathrm{~V}$ vs. $\mathrm{Ag} / \mathrm{AgCl} / \mathrm{KCl}(3 \mathrm{M})$ in order to clearly distinguish anodic dissolution from the 304 steel (Figure 7B), whereas the 316 steel remained inactive. Some crevice corrosion was imaged as well, since dissolution mainly occurred at the edges of the metal surface. This potential is lower than the reported pitting potential for 304 steel in this solution [23], though two facts possibly influencing the pitting potential shift should be noticed: (1) the previous application of the cathodic potential held during the first scan, which may have produced a partial electrochemical reduction of the oxide layer, and (2) the potentiostatic conditions applied in this work, different from the potentiodynamic polarization techniques commonly employed to establish pitting corrosion values. Local breakdown of the oxide layer resulting in pitting corrosion occurred at this positive potential for the 304 surface but not for the 316 steel. The latter required a rather high positive bias, namely $+1.20 \mathrm{~V}$ vs. $\mathrm{Ag} / \mathrm{AgCl} / \mathrm{KCl}(3 \mathrm{M})$, in order to distinguish some anodic process taking place on distributed sites on the surface (see Figure 7C). As expected, vigorous corrosion operated on the 304 strip at this potential. 
In summary, scanning microelectrochemical techniques can be employed to visualize the localized breakdown of passive layers on stainless steels and to identify the metal species released at the anodic sites with spatial resolution. Furthermore, the different corrosion resistance of two different steels, namely 304 and 316, was easily screened in one single experiment using scanning microelectrochemical methods. The method involves inclusion of the materials in a common mount whereas they are electrically connected at the rear. In this way, the effect of either galvanic coupling or potentiostatic polarization can be investigated whereas spatially resolved data provide information on the nature and distribution of the corrosive attack. More interestingly, this procedure can be extended to the investigation of surface treatments applied to the materials, including the action of corrosion inhibitors.

\section{Conclusions}

Operation of the scanning electrochemical microscope and the scanning vibrating electrode technique on polarized 304 and 316 stainless steels allowed monitoring the localized corrosion processes that take place when they are immersed in acid chloride solution. Speciation of iron ions formed by anodic dissolution was achieved setting the potential of the microelectrode so that iron(II) and iron(III) could be imaged selectively. In this way, the release of iron(II) species from propagating pits was established independently from alloy composition and applied polarization. Yet, formation of iron(III) species can occur on the otherwise passive surface surrounding the pit when a sufficiently positive polarization is applied to the substrate. Additionally, by galvanic coupling 304 and 316 stainless steels, differences in the reactivity of both specimens regarding their susceptibility to localized corrosion were imaged in one single experiment.

\section{Acknowledgments}

This work was financially supported by the Spanish Ministry of Economy and Competitiveness (MINECO, Madrid, Spain) jointly with the European Regional Development Fund (Brussels, Belgium) under grant CTQ2012-36787. The award of a Research Training Grant to J.I. by the Spanish Ministry of Education (Programa de Formación de Personal Investigador, Madrid, Spain) is greatly appreciated.

\section{References}


1. P. Marcus, F. Mansfeld (editors), Analytical Methods in Corrosion Science and Engineering. CRC Press, Boca Raton, 2006.

2. R. Oltra, V. Maurice, R. Akid, P. Marcus (editors), Local probe techniques for corrosion research. Woodhead Publishing Ltd., Cambridge, 2007.

3. L. Niu, Y. Yin, W. Guo, M. Lu, R. Qin, S. Chen, Application of scanning electrochemical microscope in the study of corrosion of metals, J. Mat. Sci., 44 (2009) 4511-4521.

4. M.B. Jensen, D.E. Tallman, Application of SECM to corrosion studies. In: Electroanalytical chemistry: A series of advances, vol. 24 (A.J. Bard, C.G. Zoski, editors). CRC Press, Boca Raton, 2012, p. 171.

5. Y. González-García, G.T. Burstein, S. González, R.M. Souto, Imaging metastable pits on austenitic stainless steel in situ at the open-circuit corrosion potential, Electrochemistry Communications 6 (2004) 637-642.

6. A.C. Bastos, A.M. Simões, S. González, Y. González-García, R.M. Souto, Imaging concentration profiles of redox-active species in open-circuit corrosion processes with the scanning electrochemical microscope, Electrochemistry Communications 6 (2004) 1212-1215.

7. A.M. Simões, A.C. Bastos, M.G. Ferreira, Y. González-García, S. González, R.M. Souto, Use of SVET and SECM to study the galvanic corrosion of an iron-zinc cell, Corrosion Science 49 (2007) 726-739.

8. Y. Yin, L. Niu, M. Lu, W. Guo, S. Chen, In situ characterization of localized corrosion of stainless steel by scanning electrochemical microscope, Applied Surface Science 255 (2009) 9193-9199.

9. M. Terada, A. F. Padilha, A. M. P. Simões, H. G. de Melo, I. Costa, Use of SECM to study the electrochemical behavior of DIN 1.4575 superferritic stainless steel aged at $475{ }^{\circ} \mathrm{C}$, Materials and Corrosion 60 (2009) 889-894.

10. M. Terada, R. Albuquerque Marques, A. M. Simões, A. Fernando Padilha, I. Costa, Use of SECM to compare corrosion resistance of DIN W. Nr. 1.4460 high $\mathrm{N}$ and AISI 316L austenitic stainless steels in physiological solutions, Corrosion Engineering, Science and Technology 46 (2011) 599-604.

11. R. Leiva-García, R. Akid, D. Greenfield, J. Gittens, M.J. Muñoz-Portero, J. García-Antón, Study of the sensitisation of a highly alloyed austenitic stainless steel, Alloy 926 (UNS N08926), by means of scanning electrochemical microscopy, Electrochimica Acta 70 (2012) 105-111.

12. J.J. Santana, J. González-Guzmán, L. Fernández-Mérida, S. González, R.M. Souto, Visualization of local degradation processes in coated metals by means of scanning electrochemical microscopy in the redox competition mode, Electrochimica Acta 55 ( 2010) 4488-4494.

13. R.S. Lillard, Scanning electrode techniques for investigating near-surface solution current densities. In: Analytical Methods in Corrosion Science and Engineering (P. Marcus, F. Mansfeld, editors). CRC Press, Boca Raton, 2006, p. 571. 
14. J.A. Wharton, B.G. Mellor, R.J.K. Wood, C.J.E. Smith, Crevice corrosion studies using electrochemical noise measurements and a scanning electrode technique, Journal of the Electrochemical Society 147 (2000) 3294-3301.

15. H. Uchida, M. Yamashita, S. Inoue, K. Koterazawa, In-situ observations of crack nucleation and growth during stress corrosion by scanning vibrating electrode technique, Materials Science and Engineering A319-321 (2001) 496-500.

16. J.G. Yu, J.L. Luo, P. R. Norton, Investigation of hydrogen-promoted pitting by the electrochemical noise method and the scanning reference electrode technique, Langmuir18 (2002) 6637-6646.

17. H.E. Jamil, A. Shriri, R. Boulif, C. Bastos, M.F. Montemor, M.G.S. Ferreira, Electrochemical behaviour of amino alcohol-based inhibitors used to control corrosion of reinforcing steel, Electrochimica Acta 49 (2004) 2753-2760.

18. A.C. Bastos, M.G. Ferreira, A.M. Simões, Corrosion inhibition by chromate and phosphate extracts for iron substrates studied by EIS and SVET, Corrosion Science 48 (2006) 1500-1512.

19. V. Vignal, H. Krawiec, O. Heintz, R. Oltra, The use of local electrochemical probes and surface analysis methods to study the electrochemical behaviour and pitting corrosion of stainless steels, Electrochimica Acta 52 (2007) 4994-5001.

20. M. Reffass, R. Sabot, M. Jeannin, C. Berziou, Ph. Refait, Effects of $\mathrm{NO}_{2}^{-}$ions on localised corrosion of steel in $\mathrm{NaHCO}_{3}+\mathrm{NaCl}$ electrolytes, Electrochimica Acta 52 (2007) 7599-7606.

21. M. Reffass, R. Sabot, M. Jeannin, C. Berziou, Ph. Refait, Effects of phosphate species on localised corrosion of steel in $\mathrm{NaHCO}_{3}+\mathrm{NaCl}$ electrolytes, Electrochimica Acta 54 (2009) 43894396.

22. J. Izquierdo, L. Nagy, S. González, J.J. Santana, G. Nagy, R.M. Souto, Resolution of the apparent experimental discrepancies observed between SVET and SECM for the characterization of galvanic corrosion reactions, Electrochemistry Communications 27 (2013) $50-53$.

23. J. Izquierdo, L. Martín-Ruíz, B.M. Fernández-Pérez, R. Rodríguez-Raposo, J.J. Santana, R.M. Souto, Scanning microelectrochemical characterization of the effect of polarization on the localized corrosion of 304 stainless steel in chloride solution, Applied Surface Science (2014) submitted.

24. R.M. Souto, J.J. Santana, L. Fernández-Mérida, S. González, Sensing electrochemical activity in polymer coated metals during the early stages of coating degradation - Effect of the polarization of the substrate. Electrochimica Acta 56 (2011) 9596-9601. 

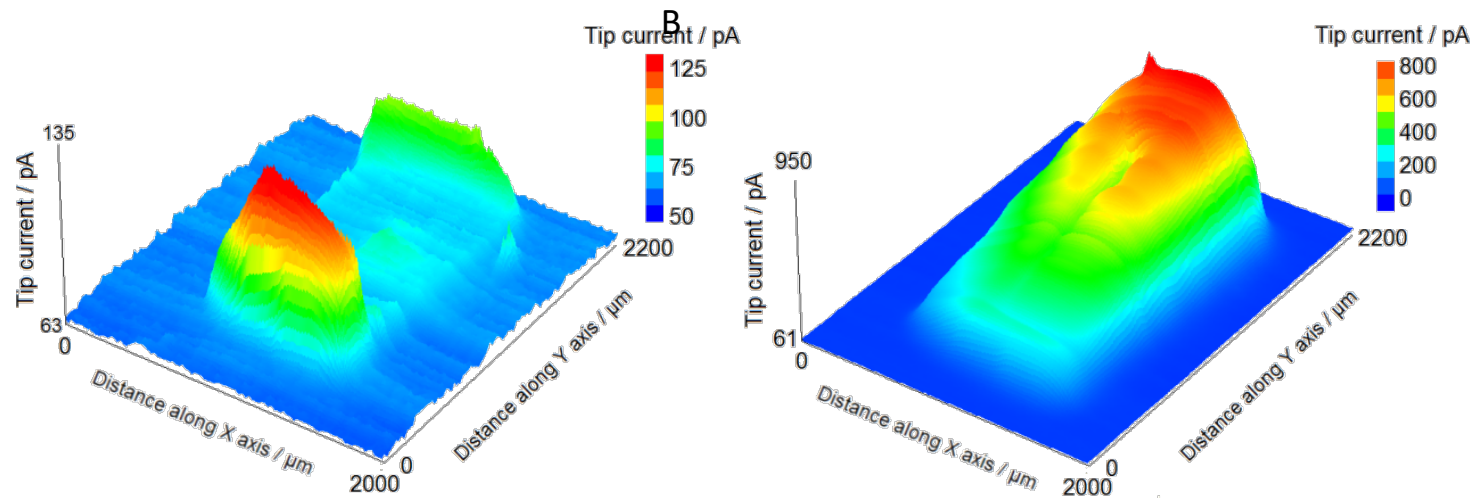

C

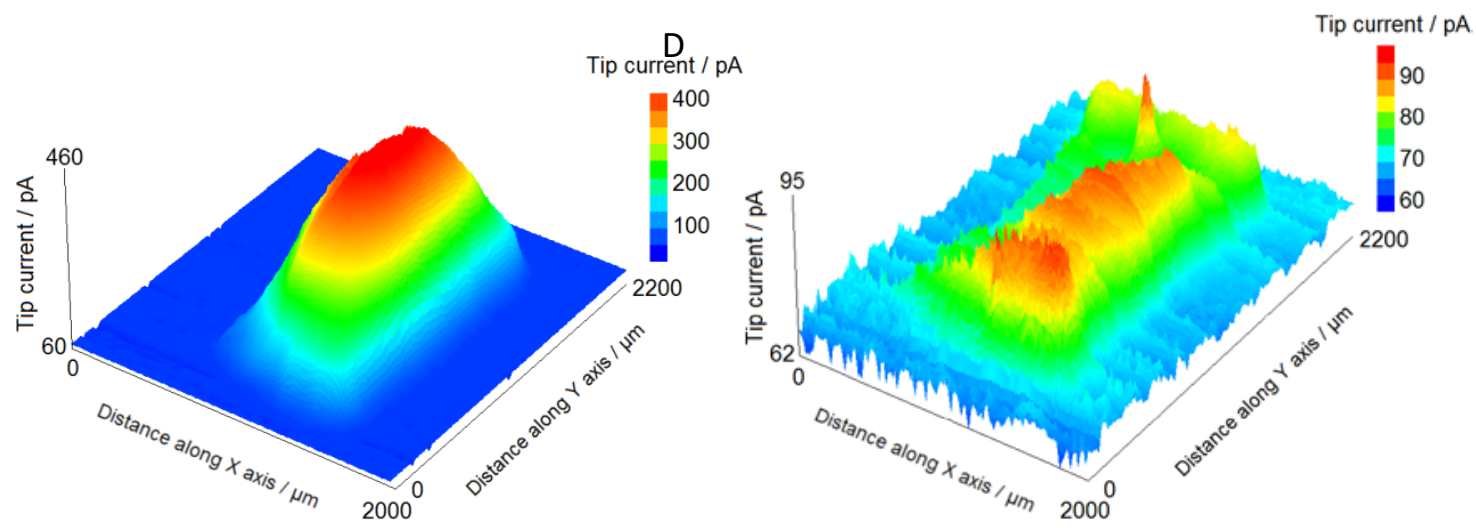

Figure 1. The distribution of iron (II) ions over a 304 steel surface exposed to $0.25 \mathrm{M} \mathrm{HCl}$ at the times: (A) 0.5, (B) 4, (C) 7.5, and (D) $24 \mathrm{~h}$. These times correspond to the initiation of scan recording. Time for scan acquisition: 3.5 hours. $E_{\text {tip }}=+0.50 \mathrm{~V}$ vs. $A g / A g C l / K C l(3 M)$; tip-substrate distance: $10 \mu \mathrm{m}$; scan rate: $25 \mu \mathrm{m} \mathrm{s}^{-1}$. The sample was left unbiased at its spontaneous open circuit potential in the solution.

A
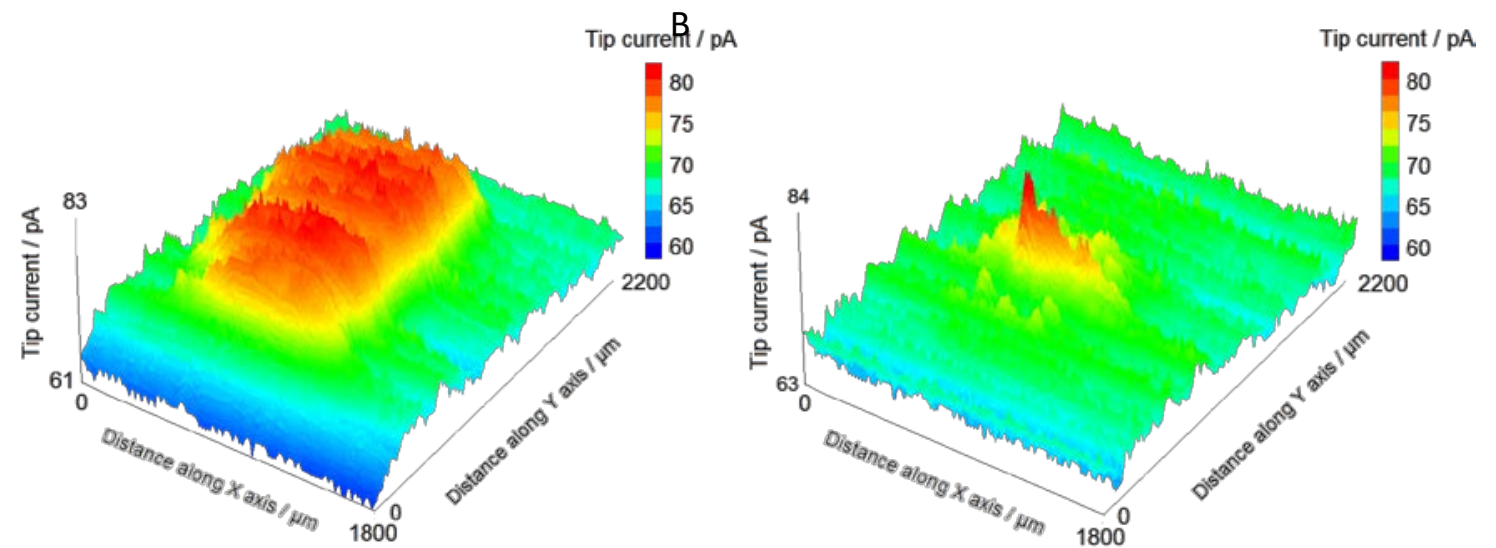

Figure 2. The distribution of iron (II) ions over a 316 steel surface exposed to $0.25 \mathrm{M} \mathrm{HCl}$ at the times: (A) 0.5, and (B) $3 \mathrm{~h}$. These times correspond to the initiation of scan recording. Time for scan acquisition: 2 hours. $E_{\text {tip }}=+0.50 \mathrm{~V}$ vs. $\mathrm{Ag} / \mathrm{AgCl} / \mathrm{KCl}(3 \mathrm{M})$; tip-substrate distance: $10 \mu \mathrm{m}$; scan rate: $25 \mu \mathrm{m} \mathrm{s}^{-1}$. The sample was left unbiased at its spontaneous open circuit potential in the solution. 
A

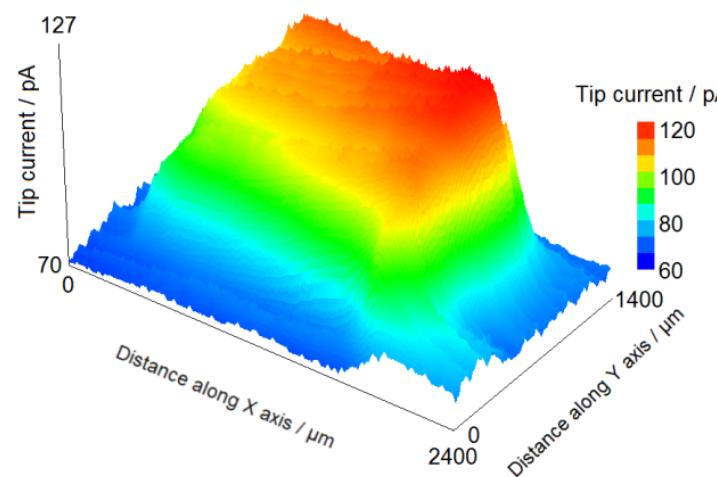

C

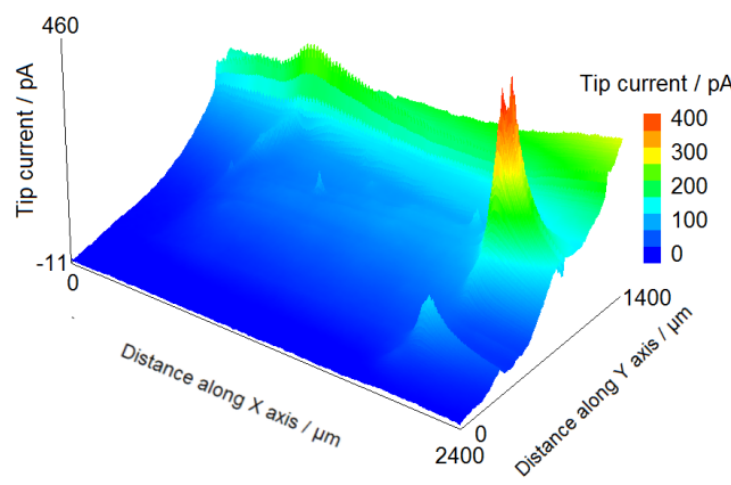

$\mathrm{E}$

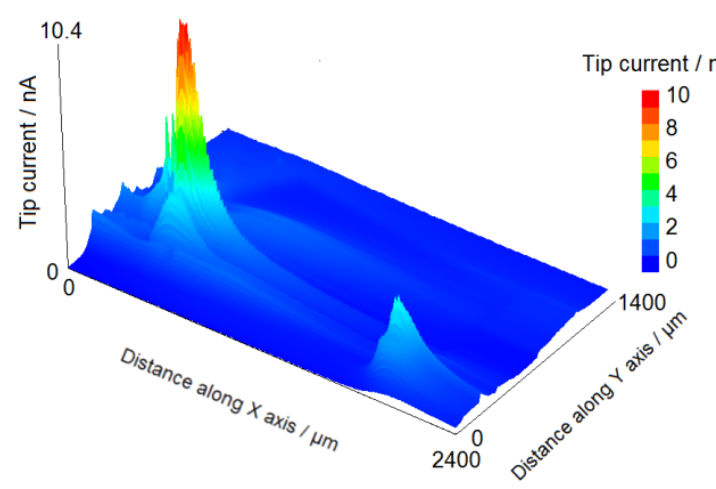

B

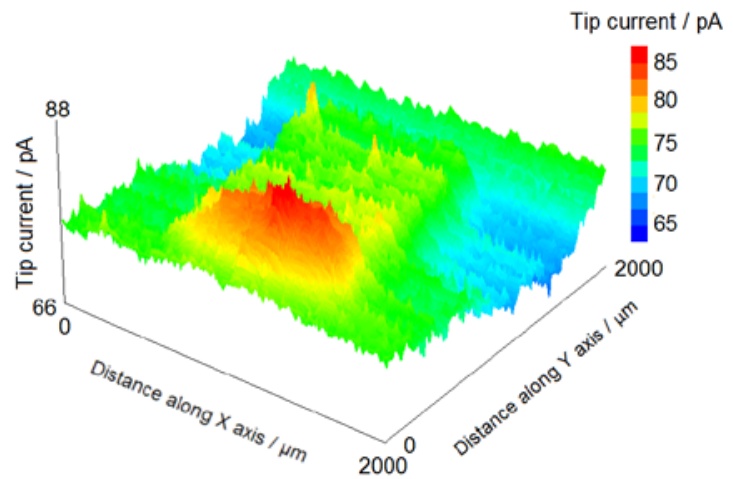

D

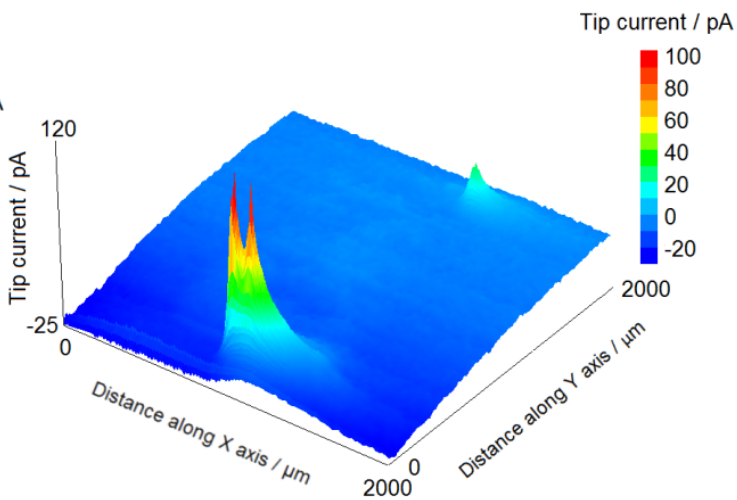

$\mathrm{F}$

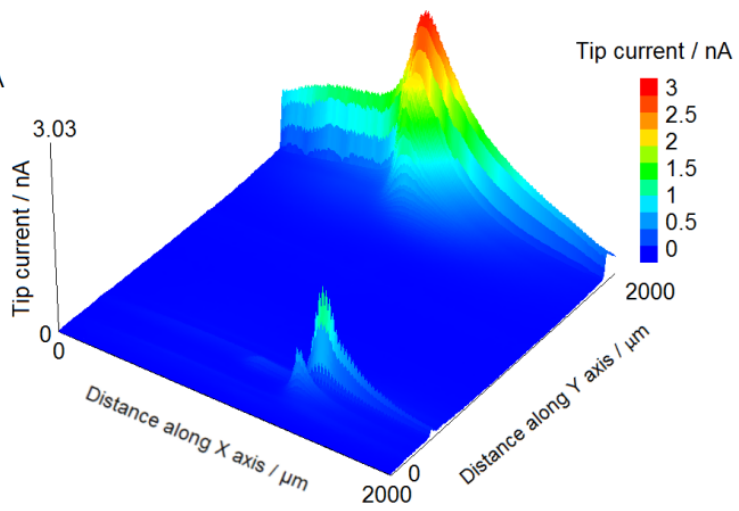

Figure 3. Effect of sample polarization on the distribution of iron (II) ions over (A,C,E) 304, and $(B, D, F) 316$ steel surfaces exposed to $0.25 \mathrm{M} \mathrm{HCl}$. Potential conditioning of the steel samples: $(A, B)$ unbiased, $(\mathrm{C}, \mathrm{D})$ polarized at $-0.10 \mathrm{~V}$ vs. $\mathrm{Ag} / \mathrm{AgCl} / \mathrm{KCl}(3 \mathrm{M})$; and $(\mathrm{E}, \mathrm{F})$ polarized at $+0.05 \mathrm{~V}$ vs. $\mathrm{Ag} / \mathrm{AgCl} / \mathrm{KCl}(3 \mathrm{M}) . E_{\text {tip }}=+0.50 \mathrm{~V}$ vs. $\mathrm{Ag} / \mathrm{AgCl} / \mathrm{KCl}(3 \mathrm{M})$; tip-substrate distance: $10 \mu \mathrm{m}$; scan rate: 25 $\mu \mathrm{m} \mathrm{s}^{-1}$. 

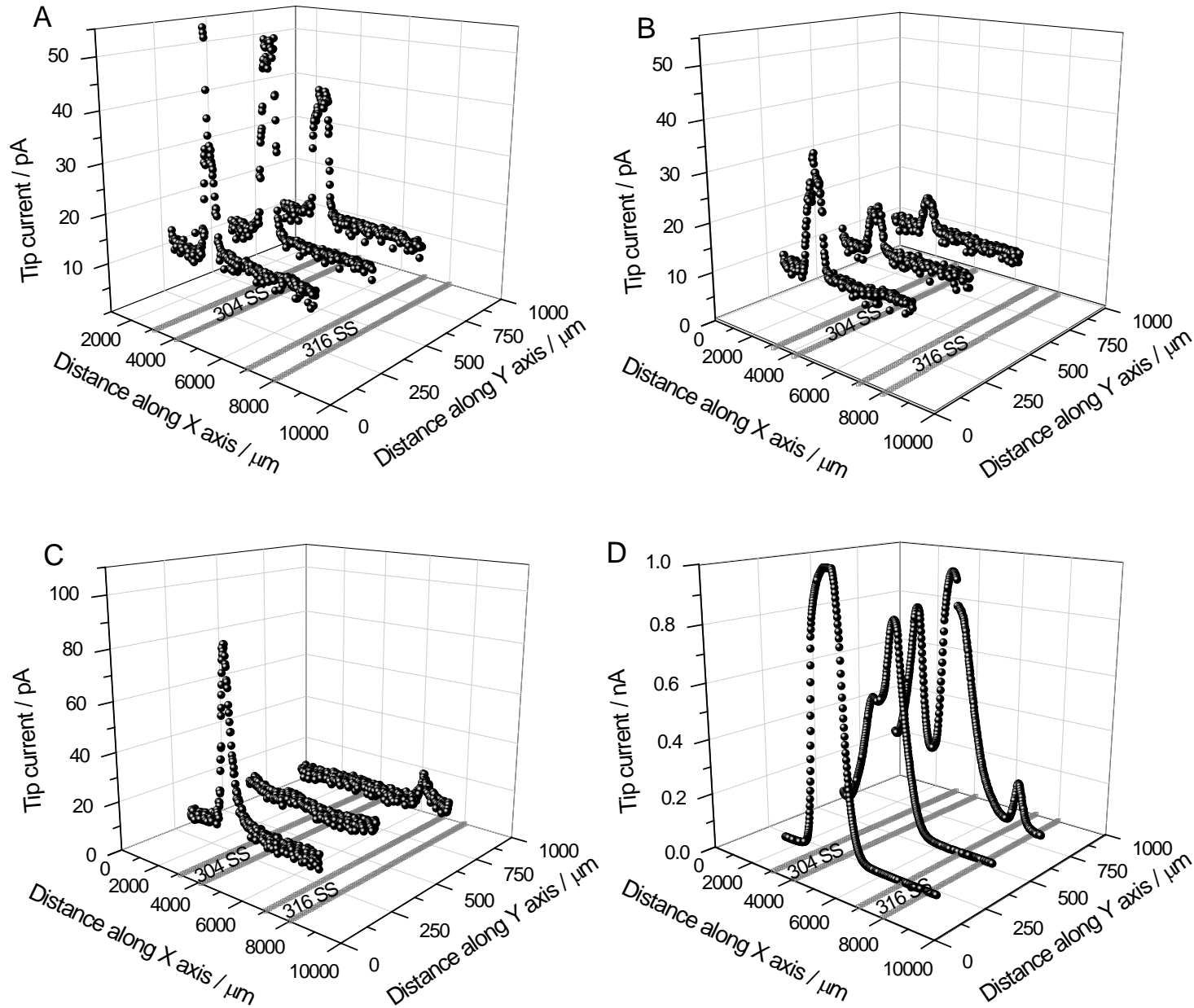

Figure 4. Effect of sample polarization on the distribution of iron (II) ions over 304 and 316 steel strips exposed to $0.1 \mathrm{M} \mathrm{HCl}$. Potential conditioning of the steel samples: (A) unbiased; (B) galvanic coupling of the two steels; or potentiostatically polarized at (C) +0.25 and (D) $+0.30 \mathrm{~V}$ vs. $\mathrm{Ag} / \mathrm{AgCl} / \mathrm{KCl}(3 \mathrm{M}) . E_{\text {tip }}=+0.50 \mathrm{~V}$ vs. $\mathrm{Ag} / \mathrm{AgCl} / \mathrm{KCl}(3 \mathrm{M})$; tip-substrate distance: $10 \mu \mathrm{m}$; scan rate: 25 $\mu \mathrm{m} \mathrm{s}^{-1}$. 

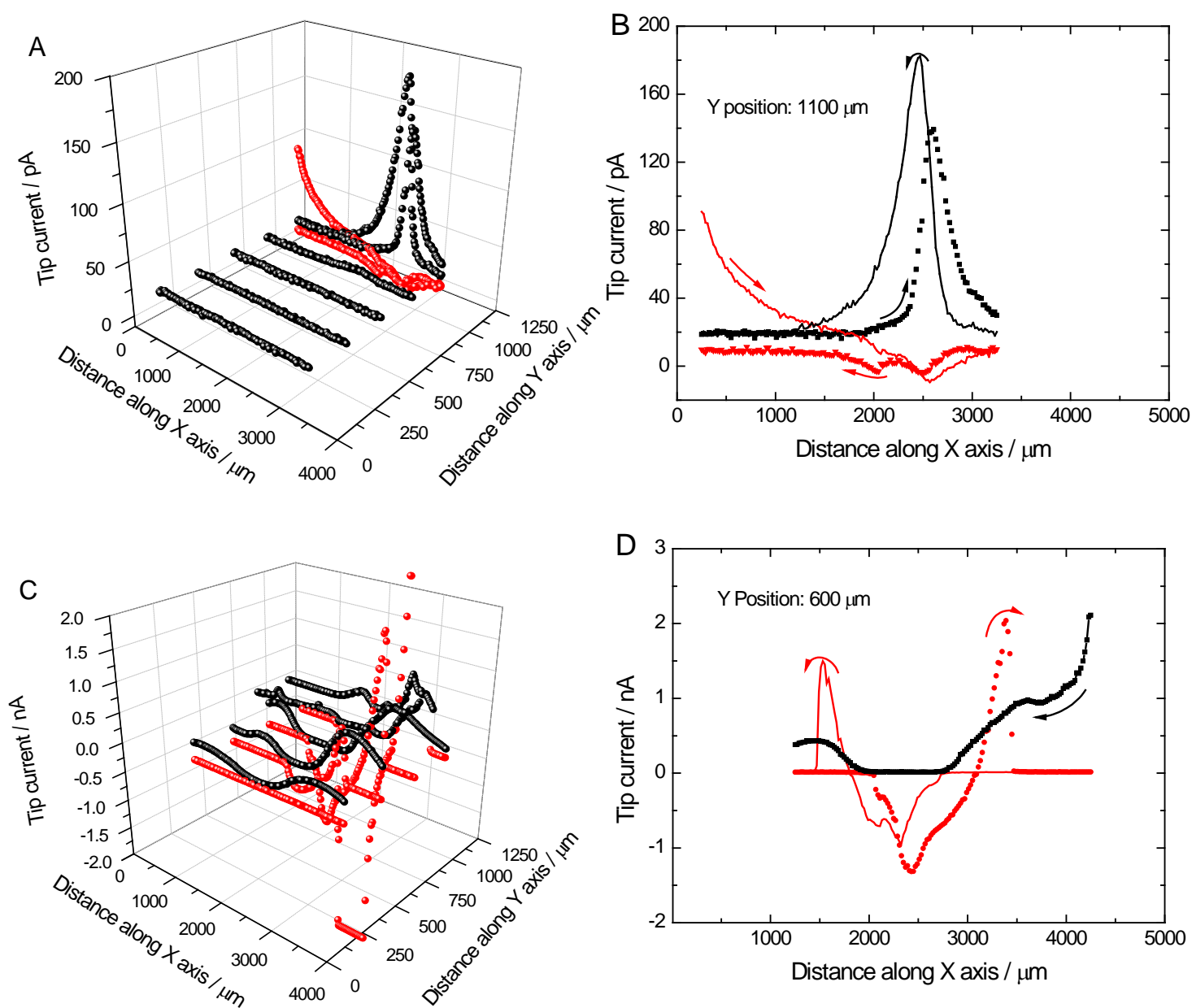

Figure 5. Effect of sample polarization on the distribution of (black) iron (II) and (red) iron (III) ions over a 316 steel strip exposed to $0.1 \mathrm{M} \mathrm{HCl}$. The steel sample was potentiostatically polarized at $(\mathrm{A}, \mathrm{B})+0.30$, and $(\mathrm{C}, \mathrm{D})+0.40 \mathrm{~V} \mathrm{vs}$. $\mathrm{Ag} / \mathrm{AgCl} / \mathrm{KCl}(3 \mathrm{M}) . E_{\text {tip }}=+0.50 \mathrm{~V} \mathrm{vs.} \mathrm{Ag} / \mathrm{AgCl} / \mathrm{KCl}(3 \mathrm{M})$ for the detection of $\mathrm{Fe}(\mathrm{II})$ ions (lines and symbols in black), and $E_{\text {tip }}=+0.10 \mathrm{~V}$ vs. $\mathrm{Ag} / \mathrm{AgCl} / \mathrm{KCl}(3 \mathrm{M})$ for the detection of Fe(III) species (lines and symbols in red). Tip-substrate distance: $10 \mu \mathrm{m}$; scan rate: 25 $\mu \mathrm{m} \mathrm{s}^{-1}$. Arrows indicate scan direction. 

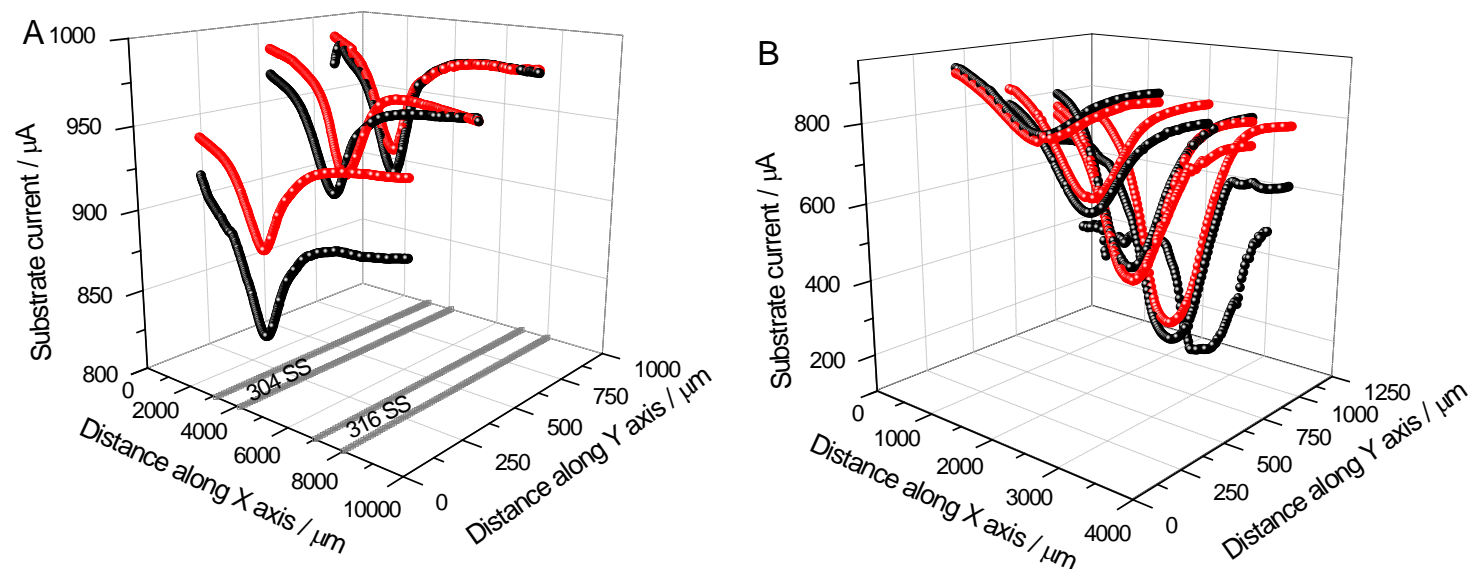

Figure 6. Current measured at the substrate immersed in $0.1 \mathrm{M} \mathrm{HCl}$ while recording SECM data as shown in Figures 4 and 5. (A) 304 and 316 steel strips were connected electrically and externally polarized using a potentiostat to $+0.35 \mathrm{~V}$ vs. $\mathrm{Ag} / \mathrm{AgCl} / \mathrm{KCl}(3 \mathrm{M})$. (B) Only 316 steel was exposed to the electrolyte, and polarization was $+0.40 \mathrm{~V}$ vs. $\mathrm{Ag} / \mathrm{AgCl} / \mathrm{KCl}(3 \mathrm{M}) . X$ and $Y$ axis refer to the position of the tip while recording the scan lines. $E_{\text {tip }}=+0.50 \mathrm{~V} \mathrm{vs}$. $\mathrm{Ag} / \mathrm{AgCl} / \mathrm{KCl}(3 \mathrm{M})$ for the detection of $\mathrm{Fe}(\mathrm{II})$ ions (lines and symbols in black), and $E_{\text {tip }}=+0.10 \mathrm{~V}$ vs. $\mathrm{Ag} / \mathrm{AgCl} / \mathrm{KCl}(3 \mathrm{M})$ for the detection of $\mathrm{Fe}(\mathrm{III})$ species (lines and symbols in red). Tip-substrate distance: $10 \mu \mathrm{m}$; scan rate: 25 $\mu \mathrm{m} \mathrm{s}^{-1}$. 
A

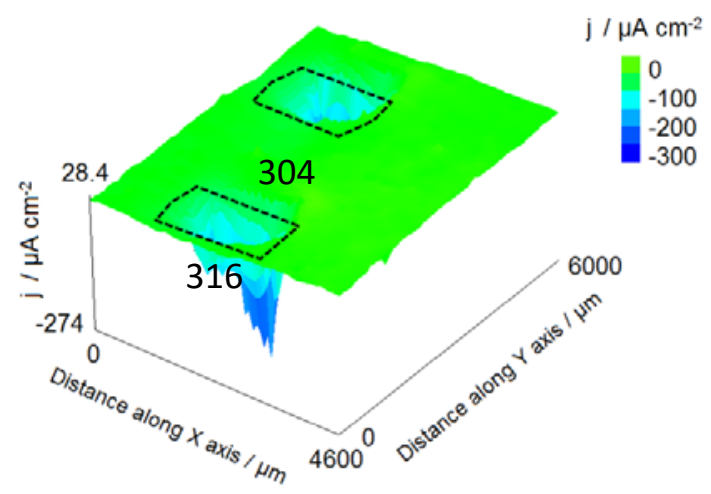

B

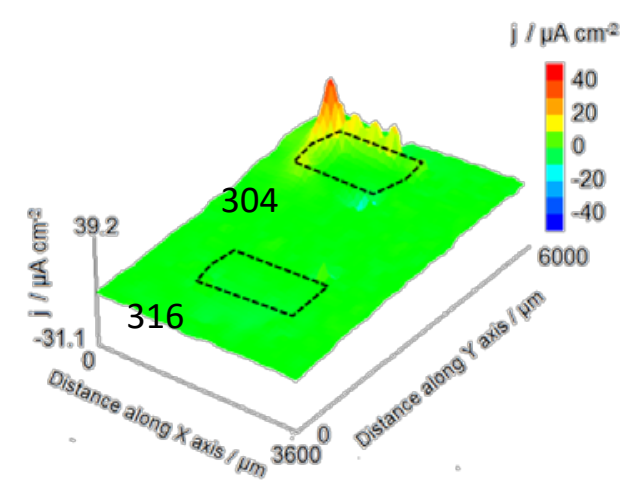

C

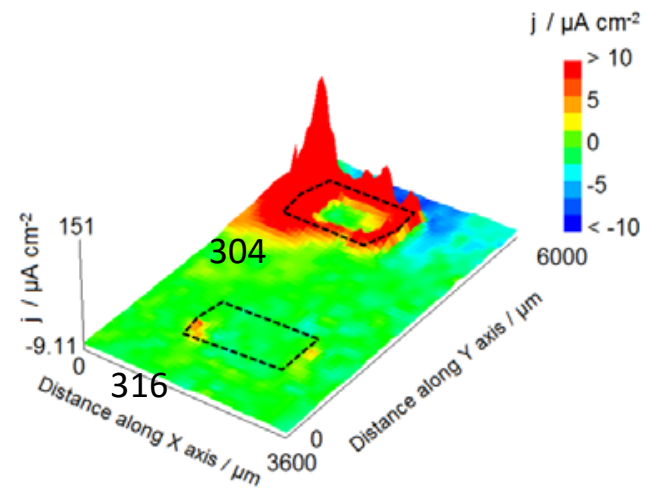

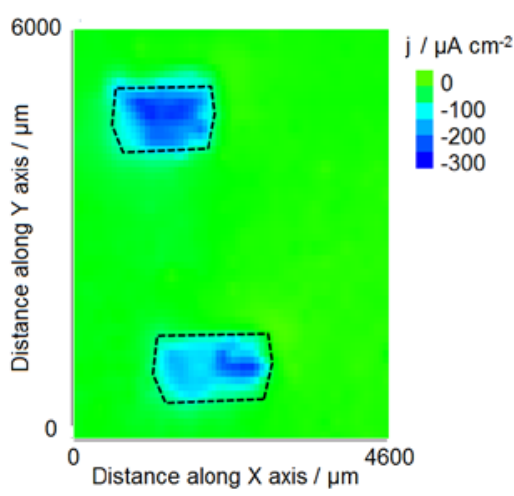
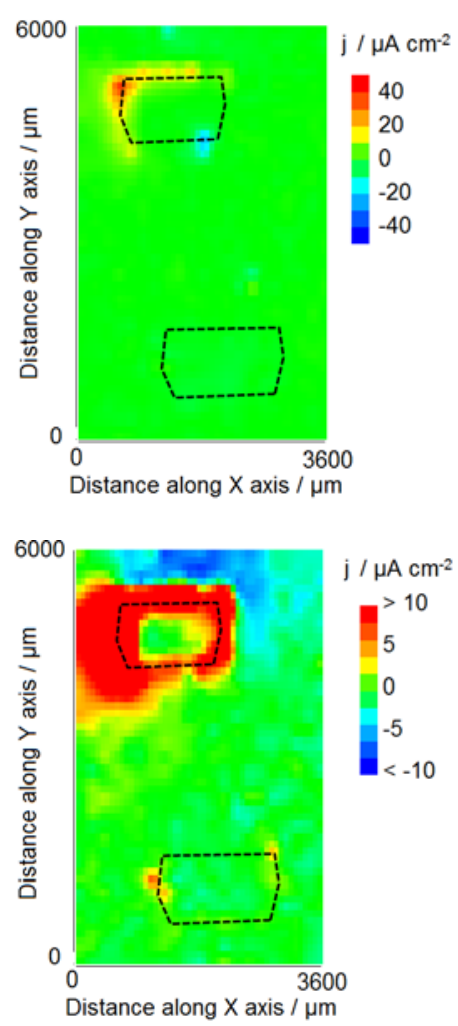

Figure 7. SVET images of 304 and 316 steel strips immersed in $0.025 \mathrm{M} \mathrm{HCl}+0.075 \mathrm{M} \mathrm{HClO}_{4} .304$ and 316 steel strips were connected electrically and externally polarized using a potentiostat to: $(A)$ $-0.75,(\mathrm{~B})+0.45$, and (C) +1.20 V vs. $\mathrm{Ag} / \mathrm{AgCl} / \mathrm{KCl}(3 \mathrm{M})$. Tip-substrate distance: $60 \mu \mathrm{m}$. 